\begin{tabular}{cc}
\hline JPPIPA, Vol.2 No.1 2017 \\
Jurnal Penelitian Pendidikan IPA
\end{tabular}

\title{
DESAIN PROGRAM DIKLAT KETERAMPILAN PROSES SAINS UNTUK GURU IPA SMP DALAM MEWUJUDKAN PEMBELAJARAN DENGAN PENDEKATAN SAINTIFIK
}

Oleh:

Asep Agus Sulaeman

Pusat Pengembangan dan Pemberdayaan Pendidik dan Tenaga Kependidikan IPA, Indonesia

\begin{abstract}
Abstrak
Kajian mendeskripsikan program diklat dalam membekalkan komponen-komponen KPS kepada guru IPA SMP dan implementasinya dalam pembelajaran dengan pendekatan saintifik. Kajian dilakukan melalui studi literatur untuk menetapkan strategi diklat dan kajian empiris melalui uji coba stretegi tersebut yang dilakukan terhadap 40 orang peserta diklat. Dalam ujicoba dijaring data tentang persepsi pemahaman pembelajaran IPA dengan KPS yang dijaring melalui kuesioner, respons peserta terhadap proses pembelajaran yang dijaring melalui open-ended question, dan respons pelaksanaan program menggunakan kuesioner. Analisis data dilakukan secara deskriptif kuantitatif dan kualitatif. Berdasarkan hasil kajian telah ditetapkan empat tujuan diklat dengan strategi melalui tahap pengenalan, pembiasaan dan otomatisasi, serta enam prinsip pelaksanaannya. Hasil ujicoba diklat juga menunjukan terdapat peningkatan pemahaman guru tentang pembelajaran dengan pendekatan saintifik dan sebagian beesar peserta diklat merespons baik terhadap pelaksanaan serta komponen diklat.
\end{abstract}

Kata Kunci : program diklat, Guru IPA, pendekatan saintifik.

\begin{abstract}
The study describes the training program in supplying the PPP components to the science teachers of SMP and their implementation in learning with the scientific approach. The study was conducted through a literature study to establish a strategy of empirical training and study through a stretegi trial conducted on 40 training participants. In the experiment, we collected data about the perception of understanding of science learning with PPP that was collected through questionnaires, participant responses to learning process which was encompassed through open-ended question, and program implementation response using questionnaire. Data analysis is done descriptively quantitative and qualitative. Based on the results of the study has been determined four training objectives with the strategy through the stage of recognition, habituation and automation, and the six principles of implementation. The results of the training test also showed that there was an increase in teachers 'understanding of learning by scientific approach and some of the participants' attitudes were well responded to the implementation and the training component.
\end{abstract}

Keywords: training program, science teacher, scientific approach.

(C) 2017 Universitas Negeri Surabaya

Alamat Korespondensi:

Pusat Pengembangan dan Pemberdayaan Pendidik

p-ISSN: $2527-7537$

dan Tenaga Kependidikan IPA, Indonesia

e-ISSN: 2549-2209

Email: agus_p3g@yahoo.com 


\section{PENDAHULUAN}

Pendidikan IPA perlu memfokuskan pada pengembangan literasi sains agar peserta didik memahami hakikat sains dan hubungannya dengan masyarakat, daripada hanya memberikan pengetahuan konten (dela Cruz, 2015; Kemdikbud 2016). Oleh karena itu, dalam pembelajaran IPA guru perlu membelajarkan dan melatihkan keterampilan merumuskan fakta, konsep dan teori, dengan mendorong peserta didik untuk melakukan penyelidikan ilmiah melalui pendekatan saintifik (Zeidan \& Jayosi, 2015; Kemdikbud 2016). Guru IPA harus mewujudkan proses pembelajaran yang dapat mempersempit kesenjangan antara konsep IPA yang diperoleh dan aplikasinya di kehidupan sehari-hari melalui kegiatan praktik di laboratorium. Kegiatan praktik ini dapat meningkatkan berbagai keterampilan intelektual dan prosedural yang nantinya berguna bagi karir masa depan peserta didik (Raj \& Devi, 2013). Salah satu cara untuk mencapai kondisi tersebut adalah penggunaan keterampilan proses sains (KPS) dalam pembelajaran IPA (Aktamis \& Ergin, 2008; Feyzioğlu, 2009; Zeidan \& Jayosi, 2015). Pembelajaran melalui KPS dapat melatihkan peserta didik proses membangun pengetahuan, memproduksi dan menggunakan informasi ilmiah, melakukan proses penelitian ilmiah, dan berlatih memecahkan masalah di lingkungannya.

Pentingnya membelajarkan IPA melalui KPS adalah agar peserta didik terampil dalam menjelaskan objek dan peristiwa, mengajukan pertanyaan atas permasalahan, membangun penjelasan ilmiah, menguji penjelasan dan pengetahuan ilmiah, serta mengomunikasikan ideidenya kepada orang lain (Abungu, et. al., 2014). Pembelajaran dengan pendekatan KPS dapat mewujudkan lingkungan belajar yang aktif, dapat menunjukkan keberkaitan antara konsep IPA dan permasalahan di kehidupan sehari-hari, serta menunjukkan proses belajar bermakna bagi peserta didik (Chebii, et al., 2012; Abungu, et. al., 2014: Raj \& Devi, 2013). dela Cruz, (2015) menyatakan bahwa proses penyelidikan ilmiah di kelas memberikan kesempatan kepada peserta didik untuk menjalani proses menggunakan metode ilmiah, sehingga mereka memperoleh pemahaman yang baik tentang hakikat IPA dalam mendapatkan solusi untuk suatu permasalahan secara sistematis dan ilmiah.

Dalam rangka membekalkan KPS dalam pembelajaran di lingkungan laboratorium dan kelas, pembelajarannya harus disiapkan oleh guru IPA agar peserta didik dapat menguasainya dengan baik (Sen \& Vekli, 2016). Oleh karena itu guru IPA SMP perlu menguasai dengan baik kompetensi berikut ini: 1) menerapkan konsep, hukum, dan teori IPA untuk menjelaskan berbagai fenomena alam; 2) menjelaskan penerapan hukum-hukum IPA dalam teknologi terutama yang dapat ditemukan dalam kehidupan sehari; 3) Menggunakan alat-alat ukur, alat peraga, alat hitung, dan piranti lunak komputer untuk meningkatkan pembelajaran IPA di kelas dan laboratorium; 4) merancang eksperimen IPA untuk keperluan pembelajaran atau penelitian; 5) melaksanakan eksperimen IPA dengan cara yang benar (NRC, 2005; Kemdiknas 2007).

Penguasaan KPS oleh guru itu sendiri sangat penting untuk dapat mengajarkan pengetahuan IPA melalui investigasi ilmiah. Guru yang akan memfasilitasi peserta didik untuk memperoleh KPS harus terlebih dahulu menguasainya dan terampil mengembangkan pembelajaran dengan pendekatan saintifik, yaitu pembelajaran yang mendorong peserta didik melakukan investigasi, bukan guru yang menjelaskan (Karamustafaoglu, 2011; Chabalengula, et al., 2012; Chebii, et al., 2012; Aydogdu, 2015). Ketika guru telah menguasai KPS, maka keuntungannya adalah guru dapat: 1) membantu peserta didik memahami topik IPA dan belajar lebih baik; 2) meningkatkan minat peserta didik; 3) meningkatkan keterampilan peserta didik; 4) membantu mereka menemukan pengetahuannya sendiri; 5) meningkatkan keterampilan pengamatan; 6) meningkatkan kemampuan memecahkan masalah; 7) memastikan peserta didik belajar melalui pengalaman sendiri.

Penguasaan KPS oleh guru sangat memengaruhi kemampuan mereka dalam mewujudkan pembelajaran IPA melalui pendekatan ilmiah. Keberhasilan pendekatan KPS bergantung pada kompetensi, antusiasme, dan rasa percaya diri dari guru IPA (Abungu et al., 2014; Sukarno, et al., 2013). Zeidan dan Jayosi (2015) menemukan hubungan yang signifikan antara seberapa baik guru memahami KPS dan sikap dalam membelajarkan sains melalui proses. Guru yang memiliki pemahaman KPS yang rendah, kecil kemungkinan mengajarkan konten IPA melalui proses penyelidikan kepada peserta didiknya (Chabalengula, et al., 2012; Raj \& Devi, 2013). Faktor-faktor lain yang memengaruhi pembelajaran IPA melalui KPS adalah kesiapan guru dalam menggunakan laboratorium, memahami inovasi teknologi di lingkungan laboratorium, dan kemampuan menghubungkan antara pekerjaan laboratorium, kehidupan seharihari, serta pengetahuan konseptual (Feyzioğlu, 2009).

Faktanya menunjukkan bahwa pendidikan calon guru IPA belum optimal membelajarkan kegiatan pembelajaran berorientasi pada aplikasi KPS yang memadai dan efektif bagi mahasiswa (Chabalengula, et al., 2012; Sen \& Vekli, 2016). Dalam berbagai studi yang dilakukan terhadap 
mahasiswa calon guru IPA menunjukkan bahwa mereka tidak cukup memiliki KPS (Feyzioğlu, 2009; Chabalengula, et al., 2012). Begitu pula di tingkat guru, sebagian besar guru IPA kurang memahami cara penyusunan rencana pembelajaran dengan pendekatan KPS ataupun pendekatan saintifik (Chabalengula, et al., 2012; Sulaeman, 2016). Kondisi ini juga sejalan dengan hasil kajian Sukarno, et al. (2013) yang juga menunjukkan bahwa pemahaman KPS guru IPA SMP yang rendah pada saat ini berimplikasi pada kegiatan belajar mengajar dengan sedikit menggunakan pendekatan ilmiah.

Mengingat pentingnya pembelajaran IPA dengan pendekatan KPS, guru-guru yang belum memenuhi kompetensi pembelajaran KPS perlu menguasainya, sehingga diperlukan program pembekalan yang tepat untuk guru IPA. Usulan tersebut sejalan dengan pendapat beberapa peneliti (Sukarno, et al., 2013; Abungu et.al., 2014; Heeralal, 2014) yang menyatakan bahwa Kementerian Pendidikan, asosiasi guru IPA, lembaga diklat guru, dan lembaga lainnya yang terkait harus menyelenggarakan lokakarya, seminar, atau pelatihan untuk melatih kembali guru IPA untuk dapat memanfaatkan kemampuan KPS dan implementasinya dalam pembelajaran.

Desain program pembekalan KPS bagi guru IPA yang dikembangkan seyogyanya bertujuan agar menjadikan guru IPA memiliki seluruh komponen KPS dengan baik sehingga dapat membekalkannya kepada peserta didik (Feyzioğlu, 2009). Selain itu, program pembekalan yang dikembangkan perlu melatihkan guru memetakan komponen KPS ke seluruh kompetensi dasar mata pelajaran IPA di SMP, merencanakan dan mengimplementasikan KPS ke dalam pembelajaran (Sen \& Vekli, 2016).

Berdasarkan latar belakang tersebut, di dalam kajian ini akan dijelaskan 1) prosedur membekalkan KPS kepada guru IPA SMP; 2) prosedur membekalkan kemampuan guru IPA untuk mengaplikasikan KPS ke dalam pembelajaran; dan 3) hasil uji coba program diklat membekalkan KPS dan implementasinya kepada guru IPA SMP. Kajian ini bermanfaat fasilitator diklat (widyaiswara, pengawas, kepala sekolah, atau guru inti) sebagai panduan pelaksanaan pembekalan, baik di lembaga diklat, maupun MGMP Kabupaten. Setelah membaca kajian ini, para fasilitator dan atau pengembang diklat dapat mengetahui langkah-langkah penting dalam rangka membekalkan KPS kepada guru IPA SMP untuk mewujudkan pembelajaran dengan pendekatan saintifik.

\section{METODE}

Kajian pengembangan program diklat dan desain prosedur diklat dilakukan melalui studi literatur. Selanjutnya, program dan desain prosedur diklat yang dihasilkan direview oleh pakar pendidikan IPA, pakar konten IPA, dan Pakar Diklat secara kualitatif. Program dan desain prosedur diklat yang telah direview selanjutnya diujicobakan.

Uji coba dilakukan melalui kegiatan workshop selama 5 hari (50 JP) dengan 40 orang peserta yang terdiri atas guru-guru IPA perwakilan dari kabupaten/kota di Provinsi Daerah Istimewa Yogyakarta dan Jawa Tengah pada tanggal 11 s.d. 15 Oktober 2016. Kegiatan difasilitasi oleh dua widyaiswara IPA dari PPPPTK IPA. Kegiatan dilakukan dengan menggunakan desain program dan prinsip-prinsip pembelajaran yang telah dijelaskan sebelumnya.

Uji coba dilakukan untuk mengetahui keberhasilan usulan desain program dan aktivitas yang telah dijelaskan. Untuk mengetahui hasil program uji coba maka dilakukan penjaringan data terhadap peserta. Dalam kegiatan ini dijaring data tentang persepsi pemahaman awal dan akhir pembelajaran IPA dengan KPS yang dijaring melalui kuesioner, respons peserta terhadap proses pembelajaran yang dijaring melalui open-ended question, dan respons pelaksanaan program menggunakan kuesioner. Analisis data dilakukan secara deskriptif kuantitatif dan kualitatif.

\section{HASIL DAN PEMBAHASAN}

Di dalam pembahasan ini dijelaskan secara rinci 1) desain program diklat untuk membekalkan KPS dan implementasinya dan 2) hasil ujicoba program diklat.

\section{Desain Program dan Prosedur Pelaksanaan Diklat}

Usulan desain program yang dijelaskan dalam pembahasan ini terdiri atas tujuan dan strategi pembekalan. Adapun komponen program yang dijelaskan terdiri atas tujuan dan strategi pembekalan, serta prinsip-prinsip pembelajarannya.

Usulan desain program yang dijelaskan dalam pembahasan ini terdiri atas tujuan dan strategi pembekalan. Adapun komponen program yang dijelaskan terdiri atas tujuan dan strategi pembekalan, serta prinsip-prinsip pembelajarannya.

Dalam membekalkan kemampuan KPS kepada guru IPA SMP terdapat minimal empat buah rumusan tujuan yang mengacu pada kemampuan dan kebutuhan guru untuk dapat mengembangkan pembelajaran dengan pendekatan KPS. Rumusan tujuan program pembekalan yang dikembangkan adalah agar guru: 1) memahami hakikat IPA dan 
komponen-komponen dalam KPS; 2) mampu mempraktikkan KPS; 3) memetakan kompetensi dasar yang dapat menggunakan pendekatan KPS; dan 4) mereview/merevisi lembar kegiatan peserta
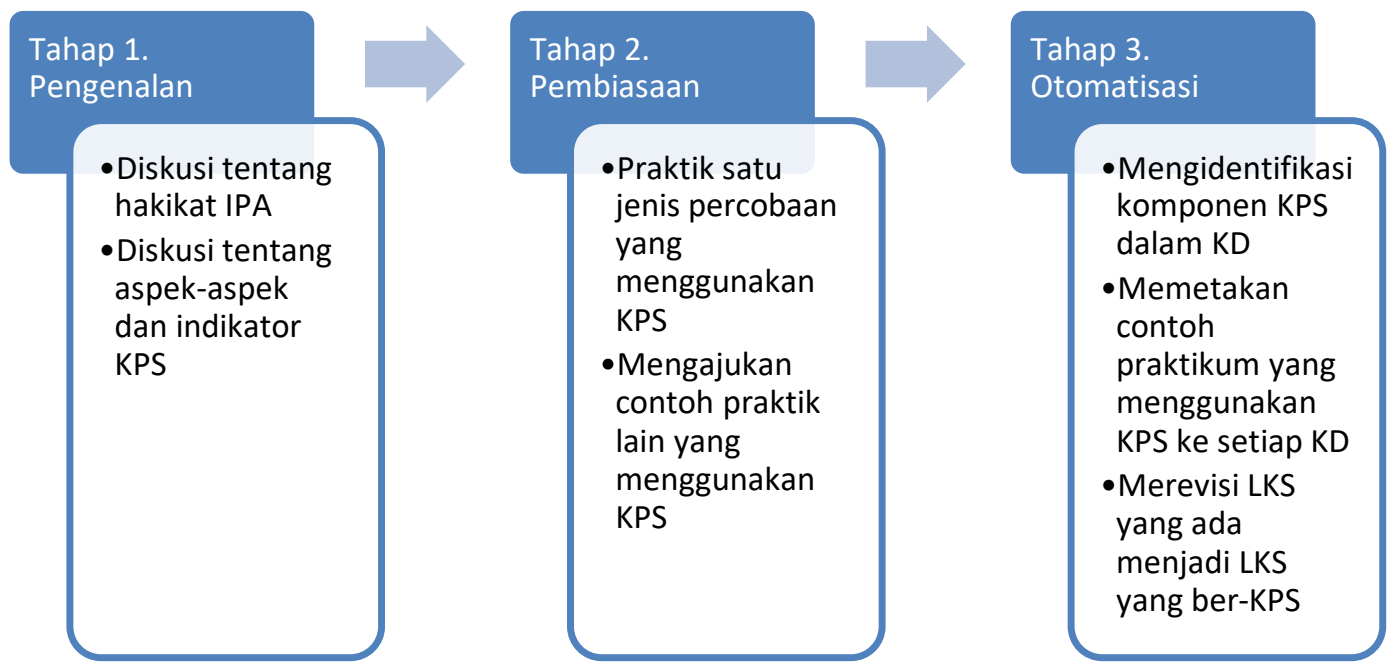

Gambar 1. Strategi Pembekalan KPS bagi Guru IPA (diadaptasi dari Saat dalam Feyzioğlu (2009))

didik yang sudah ada sebelumnya. Berdasarkan tujuan tersebut, selanjutnya dikembangkan lima kompetensi yang diajukan untuk dapat dikuasai guru, di mana hasil akhirnya adalah guru dapat memahami dan mempraktikkan komponenkomponen KPS, serta menyusun LKS-nya.

Adapun strategi pelaksanaan pembekalan menggunakan tiga tahapan pembelajaran (Saat dalam Feyzioğlu, 2009), yaitu 1) tahap pengenalan, 2) tahap pembiasaan, dan 3) tahap otomatisasi. Pada tahap pengenalan, guru difasilitasi untuk mengenal komponen-komponen KPS, yaitu keterampilan yang biasa dilakukan peneliti pada saat kerja di laboratorium. Pada tahap kedua, guru difasilitasi untuk mencoba dan menggunakan keterampilan proses dan dapat memberikan contoh keterampilan pada eksperimen lain sebagai proses pembiasaan. Pada tahap ketiga, guru dapat dengan mudah menentukan istilah yang terkait dengan KPS dan dapat menerapkannya pada situasi lain. Gambaran strategi pembekalan dapat dilihat pada Gambar 1.

Secara teknis, proses pelaksanaan pembekalan dijelaskan sebagai berikut. Pada tahap pengenalan di awal kegiatan, guru-guru IPA dibekalkan ulang pemahaman tentang hakikat IPA dan indikator masing-masing jenis KPS. Pada tahap ini peserta difasilitasi untuk berdiskusi tentang dua topik tersebut dengan tujuan agar para guru mengingat kembali dan memahaminya.

Pada tahap pembiasaan, guru difasilitasi mencoba melakukan salah satu contoh investigasi ilmiah sebagai sarana mengaplikasikan KPS untuk pembiasaan. Guru melalukan penyelidikan ilmiah, mulai dari merumuskan masalah, menentukan variabel, mempersiapkan alat dan bahan, mengobservasi, mengumpulkan data, menganalisis data, menginterpretasi data, dan mengomunikasikannya. Di akhir tahap ini, guru-guru diminta mengajukan contoh-contoh praktikum di SMP yang dapat membekalkan KPS. Tahap ini merupakan cara membekalkan keterampilan proses bagi guru.

Pada tahap otomatisasi guru-guru mengidentifikasi kompetensi dasar yang menuntut penguasaan KPS bagi peserta didiknya. Selanjutnya, guru merumuskan dan memetakan bentuk kegiatan praktikumnya. Guru juga mereview dan merivisi LKS yang sudah ada menjadi LKS yang dapat melatihkan keterampilan proses bagi peserta didiknya. Kegiatan-kegiatan pada tahap ini bertujuan melatihkan kemampuan guru untuk dapat menerapkan KPS pada praktikum/situasi yang berbeda dari contoh praktik yang telah dilakukan. Pada tahap ini merupakan cara membekalkan keterampilan mengaplikasikan keterampilan proses dalam pembelajaran IPA.

Keberhasilan pembekalan KPS kepada guru akan dipengaruhi banyak faktor, di antaranya motivasi kemampuan dan motivasi guru IPA. Hal tersebut berkaitan dengan anggapan guru bahwa KPS terasa rumit serta alat dan bahan di sekolah yang kurang memadai. Dalam rangka mengatasi kendala tersebut, proses pembekalan harus memperhatikan prinsip-prinsip berikut ini: 1) pembelajaran dilakukan secara kolaboratif; 2) 
mendiskusikan hakikat sains dan Komponen KPS; 3) pemodelan dan mempraktikkan KPS; 4) menunjukkan bahwa KPS dapat dilakukan dengan alat dan bahan sederhana; 5) menggunakan fenomena yang terdapat di kehidupan sehari-hari (kontekstual); 6) memberikan kesempatan memodifikasi LKS. Berdasarkan hasil implementasi pembekalan, prinsip-prinsip tersebut diharapkan dapat memotivasi guru untuk dapat memahami KPS dengan baik dan memotivasi mengimplementasikannya di sekolah masingmasing.

\section{Hasil Ujicoba Program Pembekalan KPS}

Hasil ujicoba menunjukkan bahwa terdapat perbedaan komposisi persepsi pemahaman awal dan akhir pembelajaran IPA dengan KPS, seperti terlihat pada Tabel 1 dan Gambar 2.

Tabel 1. Persepsi Pemahaman Awal dan Akhir Guru terhadap KPS dan Pembelajarannya

\begin{tabular}{|c|c|c|c|c|c|c|}
\hline Kode & Indikator & $\begin{array}{c}\text { Persepsi } \\
\text { Awal }\end{array}$ & $\begin{array}{c}\text { Persepsi } \\
\text { Akhir }\end{array}$ & GAP & $\begin{array}{c}\text { Keterangan } \\
\text { Persepsi } \\
\text { Awal }\end{array}$ & $\begin{array}{c}\text { Keterangan } \\
\text { Persepsi } \\
\text { Akhir }\end{array}$ \\
\hline $\mathrm{A}$ & $\begin{array}{l}\text { Penguasaan } \\
\text { Pengetahuan } \\
\text { Hakikat IPA } \\
\text { dan KPS }\end{array}$ & 63 & 84 & 21 & Baik & Sangat Baik \\
\hline B & $\begin{array}{l}\text { Penguasaan } \\
\text { Keterampilan } \\
\text { Investigasi } \\
\text { Ilmiah }\end{array}$ & 59 & 84 & 25 & Cukup & Sangat Baik \\
\hline $\mathrm{C}$ & $\begin{array}{l}\text { Kemampuan } \\
\text { Memetakan } \\
\text { KPS dalam } \\
\text { Kompetensi } \\
\text { Dasar }\end{array}$ & 64 & 84 & 21 & Baik & Sangat Baik \\
\hline $\mathrm{D}$ & $\begin{array}{l}\text { Kemampuan } \\
\text { merevisi } \\
\text { LKS }\end{array}$ & 67 & 82 & 15 & Baik & Sangat Baik \\
\hline
\end{tabular}

Berdasarkan Gambar 2 dan Tabel 1 tampak perbedaan antara persepsi pemahaman awal dan akhir peserta pembekalan, di mana di akhir pembelajaran merasakan pemahaman yang sangat baik untuk setiap komponen. Artinya, proses pembelajaran memberikan pengaruh terhadap persepsi peserta dalam pemahaman KPS dan implementasinya dalam pembelajaran.

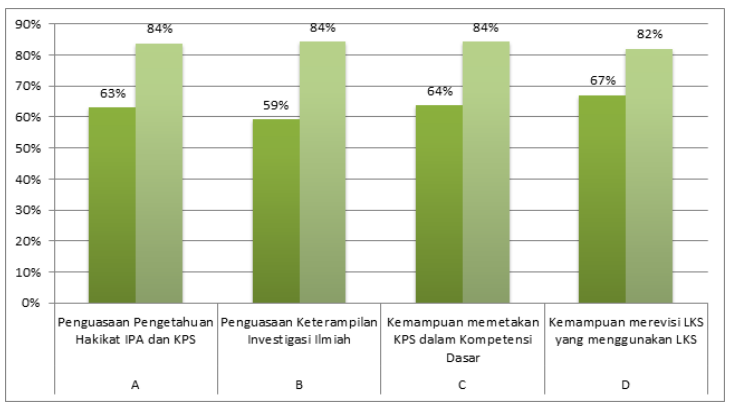

Gambar 2. Persepsi Pemahaman Awal dan Akhir Guru terhadap KPS dan Implementasi Pembelajarannya

Proses pembelajaran melalui strategi dengan tahapan pengenalan, pembiasaan, dan otomatisasi melalui prinsip-prinsip yang telah dijelaskan telah direspons dengan baik oleh peeserta. Sebagian peserta menyatakan sangat senang dan senang dengan proses pembelajaran yang dilakukan, seperti dapat dilihat di Gambar 3.

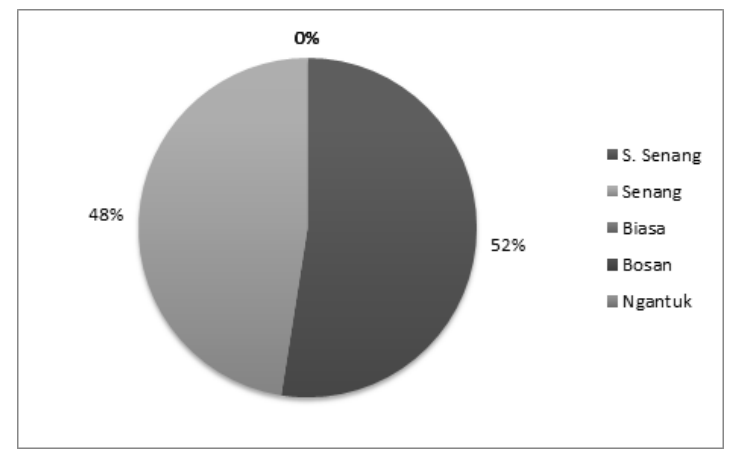

Gambar 3. Grafik Respons Peserta terhadap Proses Pembelajaran dalam Diklat

Hasil pengisian open ended question juga menunjukkan bahwa guru-guru memberikan respons yang baik. Respons guru dapat dikelompokkan menjadi guru yang merasa bertambah pengetahuan dan merasa termotivasi serta integrasi keduanya. 
Testimoni yang menunjukkan bahwa pembekalan ini memberikan pengetahuan dan KPS adalah "ada tambahan ilmu yang sebelumnya belum pernah kita terima" dan "saya mendapatkan pengetahuan KPS dan praktik tahapan-tahapan dalam KPS serta cara pencapaiannya melalui praktikum." Adapun contoh testimoni yang termotivasi untuk mengimplementasikan pembelajaran dengan KPS adalah, "saya akan lebih meningkatkan diri dalam pembelajaran keterampilan proses, khususnya dalam bidang pendidikan" dan "hal yang berbeda yang ingin saya lakukan, mencoba menerapkannya dalam KBM setiap harinya." Adapun berkaitan dengan penggunaan bahan lokal dan topik kontekstual pada kegiatan investigasi ilmiah juga direspons positif dengan pernyataan, "ternyata eksperimen dapat menggunakan alat dan bahan yang mudah didapat di sekitar kita."

Adapun respons peserta terhadap keseluruhan program pembekalan dapat dilihat pada Gambar 4. Berdasarkan gambar, peserta merespon sangat baik dan baik terhadap keseluruhan komponen program pembekalan. Artinya, komponen program pembekalan yang telah disusun dan diimplementasikan memenuhi kebutuhan dan guru merasa terfasilitasi selama melaksanakan kegiatan pembelajaran.

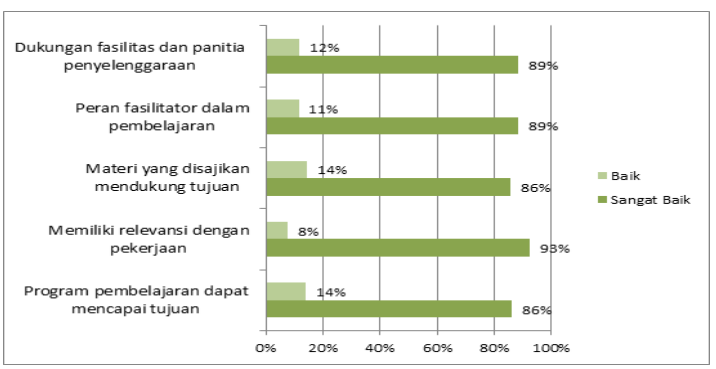

Gambar 4. Grafik Respons Peserta terhadap Proses Pembelajaran dalam Diklat

Berdasarkan hasil uji coba, peserta memberikan respons baik terhadap strategi yang dilakukan dalam pembelajaran. Hal ini berkaitan dengan kegiatan kolaboratif antarpeserta dalam membentuk pemahaman sendiri akan lebih bernilai dan lebih efisien. Keuntungan pembelajaran kolaboratif bagi pebelajar, di antaranya terjadinya diskusi sebaya yang berfungsi dalam menggabungkan pengalaman dan pengetahuan yang dimiliki sebagai cara membentuk koginiftif peserta (Cymer, 2007). Selain itu, keuntungan bekerja secara kolaboratif adalah peserta akan lebih memahami penyampaian suatu masalah atau pengatahuan dari temannya yang satu profesi daripada fasilitatornya. Dalam pembelajaran kolaboratif, peserta juga akan saling memberikan informasi dan menerima umpan baliknya yang akan sangat menguntungkan bagi peningkatan pemahaman tentang KPS.

Berdasarkan hasil uji coba, peserta juga merasa mendapatkan pengetahuan tentang KPS dan Implementasinya. Kondisi tersebut berkaitan dengan pemilihan metode diskusi dan praktik. Diskusi tentang hakikat IPA dan komponen KPS merupakan cara mengungkapkan pengetahuan awal sangat penting dalam pembelajaran orang dewasa. Kondisi ini sejalan dengan pendapat Cymer (2007) yang menyatakan bahwa pembelajaran akan berjalan secara efektif jika berdasarkan pengetahuan yang telah dimiliki oleh pebelajar. Selama ini guru-guru IPA sudah mengenal istilah Hakikat IPA dan KPS, akan tetapi mereka kurang memahami cara mengimplementasikannya (Sulaeman, 2016; Sukarno et al., 2013). Melalui tahap diskusi ini, guru-guru diingatkan kembali pengetahuan tentang Hakikat IPA. Pada akhirnya, berdasarkan kegiatan diskusi ini guru dapat termotivasi dan menyepakati pentingnya membelajarkan konsep IPA kepada peserta didik melalui KPS.

Begitu pula prosedur pembekalan melalui parktik langsung merupakan cara yang menguntungkan. Melalui praktik langsung, guru akan merasa memiliki terhadap konsep dan keterampilan yang mereka kuasai selama investigasi. Cara seperti ini telah dilakukan Sen \& Vekli (2016), di mana hasilnya menunjukkan bahwa calon guru sains mengakui pentingnya mengalami penerapan pendekatan pembelajaran KPS, setelah itu mereka baru merasakan bahwa pendekatan yang diaplikasikannya bernilai positif. Jika guru dilibatkan melakukan investigasi ilmiah, mulai dari merancang investigasi, mereka akan merasa lebih kompeten.

Guru perlu berimprovisasi menggunakan bahan dari lingkungannya untuk mempersiapkan investigasi ilmiah di kelas (Heeralal, 2014). Metode pembelajaran yang diterapkan dalam pelajaran IPA dimaksudkan untuk mempromosikan kegiatan pemecahan masalah, melalui investigasi dan proyek ilmiah dengan penggunaan bahan lokal (Abungu et.al., 2014). Akan tetapi, guru kurang pengalaman untuk berimprovisasi sehingga mereka selalu mengeluh tidak dapat melakukan kerja praktik karena kurangnya sumber daya. Penggunaan alat dan bahan lokal dalam pembekalan ini berguna juga sebagai pemodelan, sehingga guru IPA termotivasi untuk melakukan investigasi ilmiah di sekolahnya masing-masing dengan alat dan bahan yang terdapat di lingkungannya.

Guru juga difasilitasi dalam mengidentifikasi LKS yang ada dan merevisinya menjadi LKS investigasi. LKS yang telah dibuat ini dipresentasikan dan dikonsultasikan kepada 
fasilitator, Artinya, dalam kegiatan ini, fasilitator dan rekan sejawat menjadi reviewer atas LKS yang sudah diubah, sehingga hasilnya LKS investigasi. Pengubahan LKS ini memiliki 3 keuntungan, yaitu: 1) tersedianya LKS investigasi; 2) guru merasa percaya diri ketika melakukan eksperimen karena mereka merancangnya sendiri; dan 3) guru menjadi termotivasi untuk merncang LKS lainnya. Kondisi tersebut sejalan dengan pendapat Sen \& Vekli (2016) yang menyatakan bahwa guru yang merancang sendiri LKS untuk investigasi ilmiah memiliki self-efficacy untuk merancang percobaan yang berbeda.

Adapun Praktik penggunaan fenomena kontekstual dalam kegiatan ini dapat menunjukkan kepada Guru IPA bahwa pembelajaran perlu menyajikan pengetahuan yang relevan dengan kepentingan peserta didik, serta memberikan kesempatan kepada mereka untuk mengeksplorasi hubungan antara ilmu pengetahuan dan kehidupan sehari-hari (dela Cruz, 2015). Kondisi ini mencontohkan kepada guru bahwa penyajian fenomena kontekstual dapat menarik minat peserta didik dalam belajar IPA dan menggunakannya di dunia nyata. Melalui pembelajaran dengan penyelidikan contoh nyata penerapan IPA, peserta didik dapat memperoleh wawasan serta memahami keberkaitan antara IPA, kehidupan sosial, kondisi di lingkungan dan faktor etika (dela Cruz, 2015). Pembelajaran IPA dari luar sekolah yang diintegrasikan ke dalam kurikulum otentik, akan lebih melibatkan dan meningkatkan orientasi positif peserta didik terhadap sains, sehingga pembelajaran lebih menguntungkan (Yager, et al., 2012).

\section{PENUTUP}

Melalui program pembekalan ini guru IPA yang menjadi peserta akan digali kembali pengetahuan tentang pentingnya pembelajaran melalui keterampilan proses dan dibekali keterampilan tersebut serta implementasinya. Untuk mencapai kondisi tersebut, di dalam kajian ini telah uraikan rincian program, di mana program ini memiliki empat tujuan dengan strategi pelaksanaan yang terdiri atas tiga tahapan besar, serta dilengkapi dengan enam buah prinsip pelaksanaan pembelajaran. Dalam implementasinya, program pembekalan ini dapat meningkatkan pemahaman guru dan mereka merasa senang mengikuti proses pembelajarannya.

Uraian strategi pelaksanaan dan prinsip-prinsip pembelajaran merupakan prosedur yang perlu diimplementasikan dalam rangka membekalkan keterampilan proses dan implementasinya kepada guru IPA SMP. Oleh karena itu, fasilitator atau lembaga diklat yang akan melaksanakan program pembekalan dengan menggunakan strategi ini perlu memperhatikan dan menjalankan dengan baik prosedur yang telah dirumuskan dalam kajian ini. Aspek yang perlu menjadi perhatian fasilitator, yaitu perlu terus menggali topik-topik pembelajaran lainnya sebagai contoh (simulasi) investigasi ilmiah yang kontekstual dan alat bahan yang mudah diperoleh, sesuai tempat lokasi pembekalan.

Penulis berharap uraian di dalam kajian ini dapat memudahkan fasilitator, MGMP, asosiasi guru IPA, dan lembaga diklat guru dalam menyelenggarkan program pembekalan KPS kepada guru dan implementasinya, sehingga pembelajaran dengan pendekatan saintifik dapat terwujud dengan tepat. Selain itu, dengan adanya kajian ini penulis berharap juga kepada para kepala sekolah, pengawas, dan dinas pendidikan menjadi lebih termotivasi untuk berusaha memenuhi kompetensi guru IPA-nya berkaitan dengan keterampilan menyelenggarakan pembelajaran melalui pendekatan ilmiah.

\section{DAFTAR PUSTAKA}

Abungu, H. E., Okere, M. I. O., \& Wachanga, S. W. (2014). The effect of science process skills teaching approach on secondary school students' achievement in chemistry in Nyando District, Kenya. Journal of Educational and Social Research, 4 (6); hlm. 359-371

Aktamis, H., \& Ergin, O. (2008). The effect of scientific process skills education on students scientific creativity,science attitudes and academic achievements. Paper Presented at Asia-Pacific Forum on Science Learning and Teaching. June 2008.

Aydogdu, B. (2015). The investigation of science process skills of science teachers in terms of some variables. Educational Research and Reviews, 10 (5); hlm. 582-594

Chabalengula, V. W., Mumba, F., \& Mbewe, S. (2012). How pre-service teachers' understand and perform science process skills. Eurasia Journal of Mathematics, Science \& Technology Education, 8 (3); hlm. 167-176

Chebii, R., Wachanga, S., \& Kiboss, J. (2012). Effects of science process skills mastery learning approach on students' acquisition of selected chemistry practical skills in school. Creative Education 3 (8); hlm. 1291-1296

Cymer, A. (2007). Effective teaching in science: a review of literature. Journal of Turkish Science Education, 4 (1); hlm. 20-44

dela Cruz, J. P. C. (2015). Development of an experimental science module to improve middle school students' integrated science 
process skills. Proceedings of the DLSU Research Congress, Vol. 3; hlm. 1-6

Feyzioglu, B. (2009). An investigation of the relationship between science process skills with efficient laboratory use and science achievement in chemistry education. Journal of Turkish Science Education, 6 (3); hlm. 114-132

Heeralal, P. J. H. (2014). Barriers experienced by natural science teachers in doing practical work in primary schools in Gauteng. International Journal Education Science, 7(3): hlm. 795-800

Karamustafaoğlu, S. (2011). Improving the science process skills ability of science student teachers using i diagrams. Eurasian Journal Physic and Chemistry Education, 3 (1): hlm. 26-38

Kementerian Pendidikan dan Kebudayaan. (2016). Peraturan Menteri Pendidikan Dan Kebudayaan Republik Indonesia Nomor 22 Tahun 2016 Tentang Standar Proses Pendidikan Dasar Dan Menengah. Jakarta

Kemenerian Pendidikan Nasional. (2007). Standar Kualifikasi Akademik dan Kompetensi Guru. Jakarta

Khatoon, Z., Alam, M. T., Bukhari, M. A., \& Mushtaq, M. (2014). In-service teachers' perception about their competencies in delivery of biology lessons. International Journal of Asian Social Science, 4 (7); hlm. 820-834

National Research Council. (2005). How Students Learnt Science in The Classroom. Washington DC. The national Academy Press

Raj, R. G. \& Devi, S. N. (2014). Science process skills and achievement in science among high school students. Scholarly Research Journal for Interdisciplinary Studies, 2 (15); Hlm. 2435-2443

Şen, C. \& Vekli, G. S. (2016). The impact of inquiry based instruction on science process skills and self-efficacy perceptions of preservice science teachers at a university level biology laboratory. Universal Journal of Educational Research 4 (3): hlm. 603-612

Sukarno, Permanasari, A. \& Hamidah, I. (2013). Science teacher understanding to science process skills and implications for science learning at junior high school (case study in jambi). International Journal of Science and Research, 2 (6); hlm 450-454

Sulaeman, A. A. (2016). Pemahaman guru IPA SMP terhadap pembelajaran IPA berbasis inkuiri. Bingkai Sains, 1 (1); hlm. 4-14

Yager, S., O., Dogan, O, K., Haceeminoglu, E., \& Yager, R., E. (2012). The role of student and teacher creativity in aiding current reform efforts in science and technology education. National Forum of Alied Educational Research Journal, 25 (3); hlm. 1-22

Zeidan, A. H. \& Jayosi, M. R. (2015). Science process skills and attitudes toward science among palestinian secondary school students. World Journal of Education, 5 (1); hlm. 13-24. 